\title{
THE 4-BEAM LASER DiOdE ARRAY INFLUENCE ON THE COLOUR IMAGING
}

\author{
Majnaric, I.; Modric, D.; Golubovic, K. \& BolanCA, S.
}

Abstract: In this paper we investigate commercial 4-beam laser diode array with 830 $\mathrm{nm}$ laser. Experiment was performed on HP Indigo series 1000 machine. Controlled variation of the output laser power from $1 \mu \mathrm{W} / \mathrm{mA}$ to $12 \mu \mathrm{W} / \mathrm{mA}$ generates different sizes of screen elements on photoconductor. The results have been processed colorimetrically and with defining of colour difference CIE LAB $\triangle E$. Measurements demonstrate that gamut space $\Delta V$ doesn't change with variation of output laser power. Change of CMYK colors (solid tone) is negligible and $50 \%$ screen tone value experience up to ten times larger change of hue. Deviation of geometrical parameters of printed elements rises with enhancement of output laser power which generates overlap of raster elements for screen tone values beyond $50 \%$.

Key words: digital colour offset, space gamut of reproduction, CIE LAB $\triangle E$, image analysis
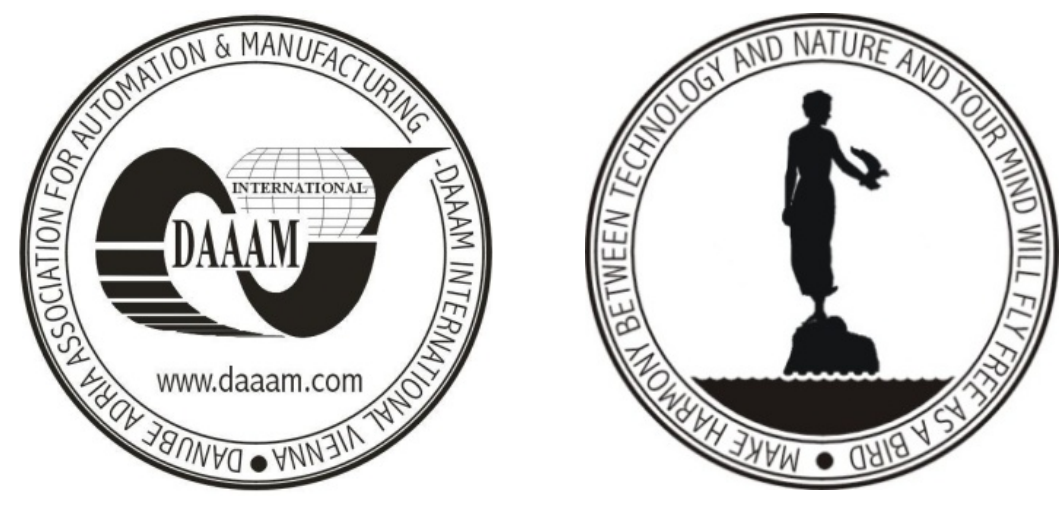

Authors' data: PhD Majnaric, I[gor]; PhD. Modric, D[amir]; BS. Golubovic, K[ristijan]; Prof. Bolanca, S[tanislav], University of Zagreb, Faculty of Graphic Arts, Getaldiceva 2, 10000, Zagreb, Croatia, igor.majnaric@grf.hr; damir.modric@grf.hr; kristijan.golubovic@grf.hr; stanislav.bolanca@grf.hr

This Publication has to be referred as: Majnaric, I[gor]; Modric, D[amir]; Golubovic, K[ristijan] \& Bolanca, S[tanislav] (2009). The 4-Beam Laser Diode Array Influence on the Colour Imaging, Chapter 10 in DAAAM International Scientific Book 2009, pp. 081-096, B. Katalinic (Ed.), Published by DAAAM International, ISBN 978-3-901509-69-8, ISSN 1726-9687, Vienna, Austria

DOI: $10.2507 /$ daaam.scibook.2009.10 